\title{
Monocular asymmetries in recognition after an eye movement: Sighting dominance and dextrality
}

\author{
CLARE PORAC \\ University of Victoria, Victoria, British Columbia V8W 2Y2, Canada \\ and \\ STANLEY COREN \\ University of British Columbia, Vancouver, British Columbia V6T IW5, Canada
}

\begin{abstract}
Although monocular recognition scores for targets presented immediately after an eye movement do not differ, the two eyes show marked recognition asymmetries when both eyes are receiving inputs but a specific target is only presented to one. In general, the right eye performs better than the left, although there are interactions with sighting dominance and the direction of eye movement.
\end{abstract}

Researchers in vision tend to treat the two eyes as if they are interchangeable for most tasks. While it is true that the left and the right eyes of visually normal human observers do not differ structurally, there are two lines of research which suggest that the eyes do not function in an equivalent fashion. The first suggestion comes from the literature on eye dominance. Although there are several types of eye dominance, the most important type appears to be sighting dominance (Coren \& Kaplan, 1973). The sighting dominant eye is defined as the eye which is habitually favored in tasks where only one eye can be used. Common tasks which illustrate the use of a sighting dominant eye include situations such as sighting through a telescope or down a rifle (Coren \& Porac, 1978). One also finds a preference for the input to the sighting eye under binocular viewing conditions where the input to the two eyes is discrepant or unfusible (Porac \& Coren, 1976). The mechanisms which underlie the preference for the sighting eye are still largely unknown. However, for many years, investigators have postulated that differences in eye-movement processes give rise to the observed asymmetries in the preferred use of one of the two eyes (Schoen \& Scofield, 1935; Walls, 1951). There is some evidence that supports this claim. For example, Schoen and Scofield (1935) reported greater fixation stability for the sighting eye, while Clark (1935) has reported data which suggest that the sighting eye performs more accurate eye movements.

This research represents the equal and shared contributions of both authors. It was supported by grants from the National Research Council of Canada and the Medical Research Council of Canada. We would like to acknowledge the assistance of Fran Theodor, who aided in the collection of the data.
There is also recent evidence which indicates information-processing differences between the sighting and the nonsighting eyes during visual tasks which require eye movements. For example, Money (1972) has shown superior performance on the part of the sighting eye during search tasks. Porac and Coren (1977) also report information-processing asymmetries as a function of eye dominance in an illusion-decrement paradigm in which the eyes scanned a common visual-geometric-illusion figure. Their findings indicate that the superiority of the sighting eye is present only under conditions where both eyes are stimulated simultaneously. When one eye is occluded, there are no asymmetries between the performance of the sighting and the nonsighting eyes. Such findings suggest that knowledge of an observer's eye dominance may be useful in predicting which eye will show the more efficient or superior performance.

There is another line of research which suggests that the right and the left eyes function differently. A number of investigators advocate the notion of a binocular controlling eye which takes the lead during complex binocular coordinations, while its contralateral partner functions in a secondary assisting capacity (Benton, 1968; Berner \& Berner, 1953; Brod \& Hamilton, 1971; Helveston, Billips, \& Weber, 1970). In general, the noncontrolling eye shows decreases in visual functioning (suppression of input) during binocular viewing situations (Helveston, Billips, \& Weber, 1970). Brod and Hamilton (1971) have suggested that the nature of habitual reading patterns in Western cultures (scans from left to right) dictate the establishment of a right controlling eye, since this would lead to a more efficient system of scanning control. They speculated that, regardless of 
sighting dominance, reading behaviors foster the development of a right controlling eye, and they were able to show that distortion of the visual input to the right eye causes more of a disruption during reading than does distortion of the input to the left.

The two lines of evidence reviewed above point toward a performance superiority which favors either the sighting dominant eye (regardless of side) or the right eye (regardless of sighting dominance), especially during situations which require eye movement. However, the body of research which has explored recognition asymmetries between the two eyes under movement conditions has not been large. Therefore, the following experiment was conducted to investigate the relationship between sighting dominance, righteyedness, and recognition performance during a simple eye-movement task.

\section{METHOD}

\section{Subjects}

From a large number of volunteers, 16 observers were selected for participation. All had 20/20 Snellen acuity in each eye, symmetrical ocular muscle balance, and normal binocular function as assessed by the Keystone Visual Skills Battery of tests. All participants were students or staff at the University of British Columbia.

Each observer was tested on two measures of sighting dominance. The first was the Miles ABC Test (Miles, 1929, 1930) in which the observer covers his or her face with the wide end of a truncated cardboard cone. With both eyes open, the subject, through the narrower aperture, views targets held by the experimenter at a distance of approximately $2 \mathrm{~m}$. The eye that is aligned with the aperture is noted. The second assessment of sighting dominance used the Point Test (Crovitz \& Zener, 1962; Palmer, 1947), which requires the observer to point at the experimenter's nose while keeping both eyes open. The two hands are used alternately for pointing, and the eye aligned with the pointing finger is noted by the experimenter. The results of these two procedures are highly correlated with other tests for sighting dominance (Coren \& Kaplan, 1973; Porac \& Coren, 1975a), and they have been used as indices of eye dominance in a number of studies (Porac \& Coren, 1975a, 1975b, 1977; Porac, Whitford, \& Coren, 1976).

Four administrations of each test were used. In order to participate in the experiment, observers were required to show consistent sighting behaviors on all eight of the repetitions of the sighting measures, in addition to meeting the visual prescreening requirements. Using these criteria, eight right- and eight leftsighters were selected.

\section{Stimuli and Procedure}

The fixation stimulus was a black outline circle, with a diameter of $30^{\prime}$ of visual arc, drawn on a white background. The reflectance of the black was $4 \%$, while that of the white background was $78 \%$. The visual display was presented in an Iconix fourchannel tachistoscope with an incident illumination of $9 \mathrm{~cd} / \mathrm{m}^{2}$.

The basic stimulus presentation sequence was as follows. The outline circle appeared in the center of the visual field and the observer was asked to fixate its center. A verbal ready signal was given and then the outline circle was displaced $4^{\circ}$ to the right or to the left. A $4^{\circ}$ displacement to initiate a saccade was chosen to avoid large eye movements involving targets which might not be visible in the periphery of both eyes. The direction of this displacement was randomly determined, and observers were instructed to shift their gaze to the circle in its new position. A target probe, consisting of either a black horizontal or a black vertical line, was presented within the displaced circle for a duration of $25 \mathrm{msec}$. The observers were asked to identify the orientation of the target probe. The interval between the offset of the circle in its central position and the presentation of the test probe in the displaced position was varied from 200 to $475 \mathrm{msec}$. There were 12 possible delay intervals which differed from each other by $25 \mathrm{msec}$. These delay intervals were presented in a random order. Thus, each trial involved an initial fixation, a displacement of the outline circle to either the right or to the left of fixation, and a presentation of a post-eye-movement target within the circle at some time after the displacement. This procedure should assess recognition performance in the immediate postsaccadic interval.

Two exposure conditions were employed. Either the observer viewed the stimulus presentation with one eye occluded (monocular viewing) or both eyes were kept open but different test probes were presented separately to each of the two eyes (binocular viewing). The binocular exposure was accomplished by placing orthogonally oriented Polaroid filters within the fields of the tachistoscope which separated the two eyes' views. This type of exposure condition, where all of the stimuli except the crucial test targets are visible to both eyes, has been called equivalence occlusion (Lehmkule \& Fox, 1976; Porac \& Coren, 1977). In the binocular viewing condition, the horizontal and the vertical lines were presented on each trial, except that on one-half of the trials the vertical line was shown to the right eye while the horizontal line was simultaneously presented to the left, and on one-half of the trials the converse was true. There were an equal number of right and left displacements for each test probe by eye combination at each fixation-probe time interval. There were 192 monocular presentations and 96 binocular viewing trials.

Observers were given four alternative identification responses. They could respond that they saw a horizontal line, a vertical line, both a horizontal and a vertical line, or nothing in the circle after the eye movement. Each observer participated in both exposure conditions.

\section{RESULTS AND DISCUSSION}

The number of correct responses was scored separately for each eye in each exposure condition. When the observer responded either "horizontal" or "vertical," this was scored as a correct response, and a response of "nothing" was scored as a miss for each eye. When the observer responded that both the horizontal and the vertical lines were present, a correct response for both the right and the left eyes was recorded. This scoring procedure was used in both the binocular and the monocular exposure conditions so that the probability of a correct response could be compared across these conditions. The performance of each eye was then converted to a probability correct score.

As a first analysis, the effects of sighting dominance on recognition scores were considered. These results are shown in Figure 1. Since there were no significant differences in performance as a function of the different fixation-probe time intervals, all analyses were collapsed across this variable.

The sighting and the nonsighting eyes show equivalent recognition performances under monocular exposure conditions (as shown in Figure 1A), where 
A

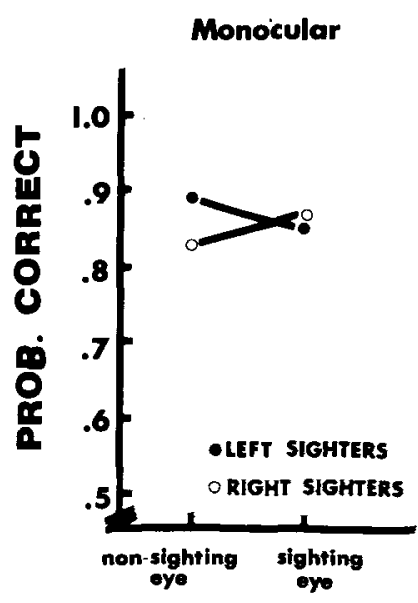

B

Binocular

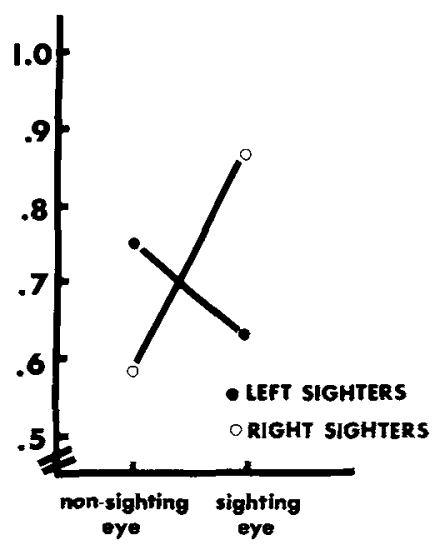

TARGET LOCATION
C

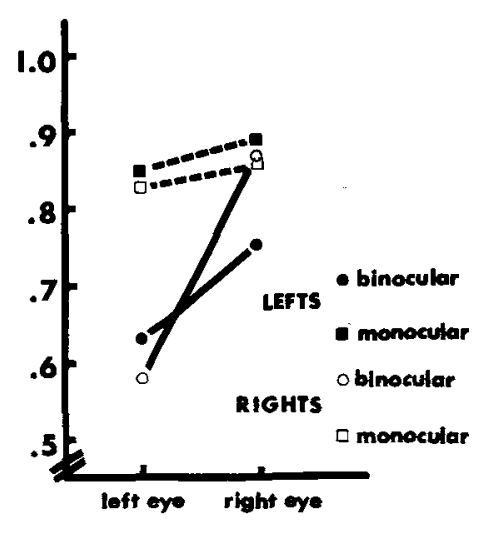

Figure 1. The effects of sighting dominance on recognition following an eye movement. (A) Monocular performance; (B) binocular performance; (C) replot of data from 1B showing right-eye recognition superiority for both right- and left-sighters.

each eye averages a probability correct of about .86 . There is no significant difference between the sighting and the nonsighting eyes $[\mathrm{F}(1,14)=.02]$, nor is there any difference between the scores of right- and leftsighters $[\mathrm{F}(1,14)=.18]$.

Under conditions of binocular exposure, where both eyes are simultaneously stimulated with different target probes, there is a different pattern of results (as shown in Figure 1B). Once again, there is no difference between right- and left-sighters $[F(1,14)=$ $2.98]$ and there is no significant difference as a function of sighting dominance $[F(1,14)=.37]$; however, there is a highly significant interaction between the types of sighting dominance (right vs. left) and the eye that receives the target $[F(1,14)=17.72, p<.001]$. This interaction indicates that regardless of sighting dominance, the right eye seems to show a greater recognition ability in this post-eye-movement task when both eyes are open. The pattern can be seen more readily by recasting the data in terms of the right vs. the left eye for the two groups of sighters. This is replotted as the solid lines in Figure 1C. Reanalysis of the data in this form again shows no significant effects of sighting dominance $[F(1,14)=$ $.37]$, but there is a right-eye superiority under the binocular viewing conditions regardless of the type of sighting dominance $[\mathrm{F}(1,14)=17.72, \mathrm{p}<.001]$. Recasting the monocular data in terms of right and left still shows no effect $[F(1,14)=.18]$. These data are replotted as the dotted lines in Figure 1C.

Further. consideration of Figure $1 \mathrm{C}$ reveals an interesting aspect of the relationship between posteye-movement recognition and the two exposure conditions used in the study. Recognition accuracy of the left eye is much lower in the binocular than in the monocular viewing condition, and this difference can be directly demonstrated. There is no significant difference between binocular and monocular performance for the right eye in either the right-sighting group $[\mathrm{t}(7)=1.77]$ or the left-sighting group $[\mathrm{t}(7)=$ $-.13]$. On the other hand, both groups show a significant decrease in the performance of the left eye under binocular exposure conditions $[t(7)=3.56$, $\mathrm{p}<.01$, for the right-sighters and $\mathrm{t}(7)=2.37, \mathrm{p}<$ .05 , for the left-sighters]. This suggests that the presence of a stimulus input in the right eye suppresses the recognition of an input to the left eye. This speculation is somewhat supported by recent neurophysiological evidence which indicates the possibility of contralateral inhibition between the two monocular channels. This contralateral inhibition probably occurs at the point where the two input channels converge (Bishop, 1973; Henry, Bishop, \& Coombs, 1969; Jung, 1961; Sanderson, Darian-Smith, \& Bishop, 1969). Such inhibitory processes have been suggested as an explanation of such visual phenomena as binocular rivalry, where the input from one eye momentarily dominates the binocular view while the input to the contralateral eye is suppressed (Fox \& Herrman, 1967; Walker, 1978). The present data would suggest that such inhibition may not be completely reciprocal and symmetrical under certain circumstances. Rather, there seems to be a selective suppression of the sinistral channel when there is input presented to both eyes in the time period immediately following a saccade. This result is consistent with clinical reports pertaining to amblyopia ex anopsia, which is a clinical condition in which the 
input from one eye is suppressed with no apparent physiological cause. The evidence suggests that the amblyopically suppressed eye is more often the left, rather than the right eye (Coren \& Duckman, 1975). These data are also consistent with the notion of a right-sided controlling eye, which takes the lead during binocular eye-movement tasks and whose input receives preferential treatment (Brod \& Hamilton, 1971; Helveston, Billips, \& Weber, 1970). The etiology of the suppression of the left channel may be experiential in nature, perhaps due to the leftto-right scan patterns required to read (Greenspan, 1976).

If such is the case, one might expect to find some interaction between recognition performance and the direction of eye movement prior to target presentation; therefore, the binocular presentation trials were reanalyzed in terms of the direction of eye movement. This analysis demonstrates some additional asymmetries between the eyes. Following an eye movement to the right of the fixation point, recognition scores are significantly higher for the sighting dominant eye $[\mathrm{F}(1,14)=7.27, \mathrm{p}<.02]$. This datum is shown in Figure $2 \mathrm{~A}$. When the movement is to the left of the fixation position, there is a different pattern of results, as shown in Figure 2B. In this latter instance, there is a significant interaction between the type of sighting dominance which an observer displays and the recognition performance in each eye $[F(1,14)=30.42, p<.001]$. As before, the presence of such an interaction indicates that there is a right-eye performance superiority during leftward eye movements, regardless of the observer's side of sighting dominance. This can be seen more readily if one recasts the data as shown in Figure $2 \mathrm{C}$. Now the interaction becomes a main effect, indicating that the right eye identifies target probes with greater accuracy immediately following a leftward eye movement $[F(1,14)=30.42, p<.001]$.

When the direction of the eye movement is taken into account, one finds that, under some conditions, the sighting eye demonstrates better recognition, while under others, the dextral eye performs more accurately. The sighting eye displays its superiority following rightward movements, while the right eye, regardless of sighting dominance, shows better performance following movements made to the left of fixation.

The results of this experiment indicate that the two eyes do not function in an equivalent fashion during recognition tasks immediately following eye movements. Although the two eyes are equally efficient under monocular conditions (where one eye is occluded), binocular recognition tends to favor the input to the right eye. Under these latter conditions, the left eye seems to be suppressed, since its performance is below that seen under monocular testing. Knowledge of an observer's sighting dominance characteristics can serve to better predict an observer's recognition accuracy if the direction of the eye movement preceding the recognition task is taken into account. Right-sighters always show a performance asymmetry which favors the sighting eye; however, the performance of left-sighters varies with the direc-
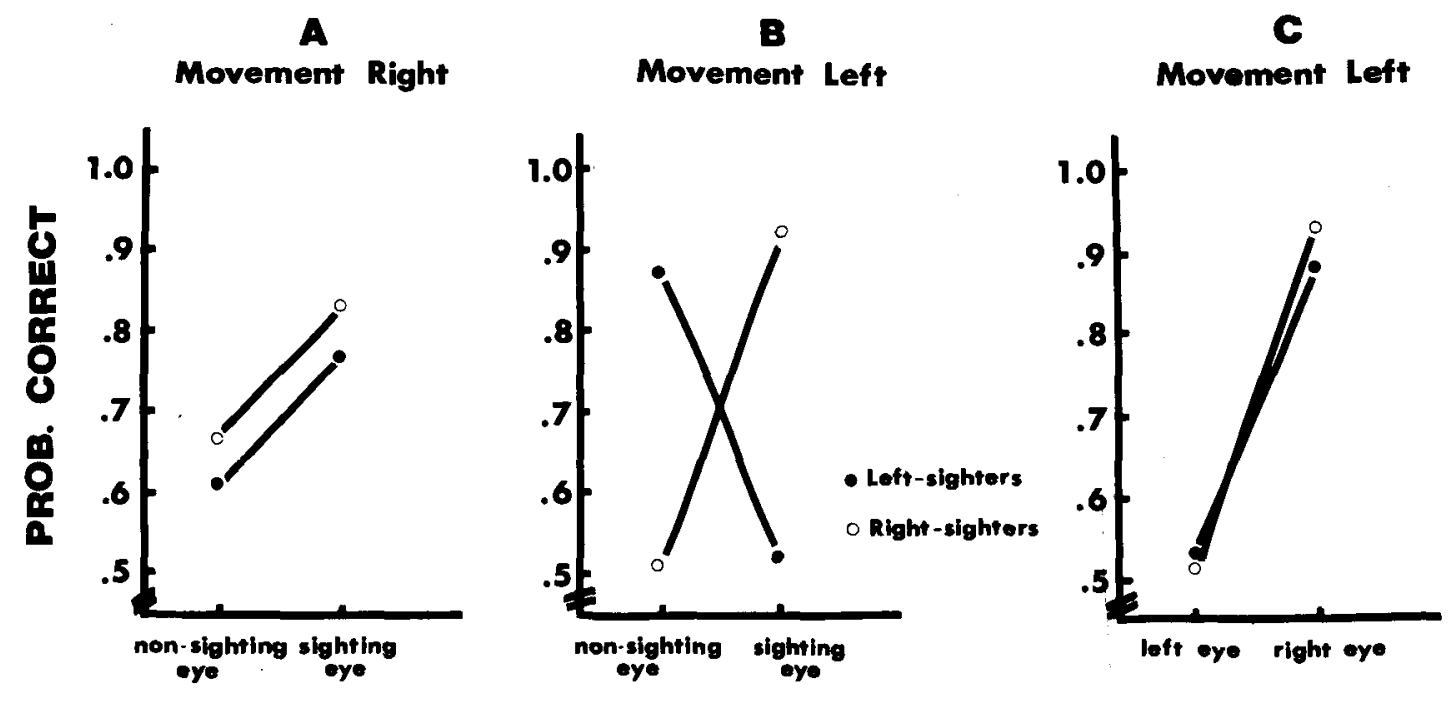

TARGET LOCATION

Figure 2. Directional analysis of binocular recognition scores. (A) Sighting eye superiority after rightward movements; (B) interaction between type-of-sighting dominance and recognition superiority after leftward movements; (C) replot of data in 2B showing righteye superiority for both types of sighters following a leftward movement. 
tion of the preceding eye movement. Porac and Coren (1976) proposed that the two eyes might not function in an equivalent fashion during binocular viewing and they pointed to sighting dominance as one example of this asymmetry. These data support this notion but also indicate that monocular asymmetries during binocular vision may be related to the nature of the task, as well as to any stable sightingdominance characteristics displayed by observers.

\section{REFERENCES}

Benton, C. D. Management of dyslexia associated with binocular control abnormalities. In A. H. Keeney \& V. T. Keeney (Eds.), Dyslexia: Diagnosis and treatment of reading disorders. St. Louis: Mosby, 1968.

Berner, G. E., \& Berner, D. E. Relation of ocular dominance, handed ness, and the controlling eye in binocular vision. A.M.A. Archives of Ophthalmology, 1953, 50, 603-608.

Bishop, P. O. Neurophysiology of binocular single vision and stereopsis. In R. Jung (Ed.), Handbook of sensory physiology (Vol. 7). New York: Springer, 1973.

Brod, N., \& Hamilton, D. Monocular-binocular coordination vs. hand-cye dominance as a factor in reading performance. American Journal of Optometry and Archives of the American Acudemy of Optometry, 1971, 48, 123-129.

Clark, B. The effect of binocular imbalance on the behavior of the eyes during reading. Journal of Educational Psychology, 1935. 26. $530-538$.

Coren, S., \& Duckman, R. Ocular dominance and amblyopia. American Journal of Optometry and Physiological Optics, 1975, $52,47-50$.

Coren, S. \& Ka Plan, C. P. Patterns of ocular dominance. American Journal of Optometry and Archives of the American Academy of Optometry. 1973, 50, 283-292.

COREN, S., \& PORAC, C. The validity and reliability of self-report items for the measurement of lateral preference. British Journal of Psychology, 1978, 69, 207.211.

Crovitz, H. R., \& Zener, K. A group test for assessing hand and eye dominance. American Journal of Psychology, 1962, 75, 271-276.

Fox, R. \& \& Herrmann, J. Stochastic properties of binocular rivalry alternations. Perception \& Psychophysics, 1967, 2, 432-436.

Greenspan, S. B. Survey of student research in behavioral and developmental optometry. American Journal of Optometry and Physiological Optics, 1976, 53, 797-802.
Helveston, E. M., Billips, W. C., \& Weber, J. C. Controlling eye-dominant hemisphere relationship as factor in reading ability. American Journal of Ophthalmology, 1970, 70, 96-100.

Henry, G. H., Bishop, P. O., \& Coombs, J. S. Inhibitory and subliminal excitatory receptive fields of sample units in cat striate cortex. Vision Research, 1969, 9, 1289-1296.

JUNG, R. Neuronal integration in the visual cortex and its significance for visual information. In W. A. Rosenblith (Ed.), Senson communication. New York: Wiley, 1961.

Lehmкule, S. W.. \& Fox, R. On measuring interocular transfer. Vision Research, 1976, 16, 428-430.

Miles. W. R. Ocular dominance demonstrated by unconscious sighting. Journal of Experimental Psychology, 1929, 12, 113-126.

MiLES, W. R. Ocular dominance in human adults. Journal of General Psychology, 1930, 3, 412-420.

MONEY, J. Studies on the functioning of sighting dominance. Quarterly Journal of Experimental Psychology, 1972, 24, 454-464.

Palmer, M. F. Studies in clinical techniques. Journal of Speech Disorders, 1947, 12, 415-418.

Porac, C., \& Coren, S. Is eye dominance a part of generalized laterality? Perceptual and Motor Skills, 1975, 40, 763-769. (a)

Porac, C., \& Coren, S. Suppressive processes in binocular vision: Ocular dominance and amblyopia. American Journal of Optometry and Physiological Optics, 1975, 52, 651-657. (b)

Porac, C., \& Coren, S. The dominant eye. Psychological Bulletin, 1976, 83, 880-897.

Porac, C., \& Coren, S. The assessment of motor control in sighting dominance using an illusion decrement procedure. Perception \& Psychophysics, 1977, 21, 341-346.

Porac. C., Whitford, F. W., \& Coren, S. The relationship between eye dominance and monocular acuity: An additional consideration. A merican Journal of Optometry and Physiological Optics, 1976, 53, 803-806.

Sanderson, K. S., Darian-Smith, I., \& Bishop, P. O. Binocular corresponding receptive fields of single units in the cat dorsal lateral geniculate nucleus. Vision Research, 1969. 9. 1297-1303.

SChoen, Z. J., \& Scofield, C. F. A study of the relative neuromuscular efficiency of the dominant and the nondominant eyes in binocular vision. Journal of General Psychology, 1935, 11, $156-181$.

WALKER, P. Binocular rivalry: Central or peripheral selective processes? Psychological Bulletin, 1978, 85, 376-389.

WALLS. G. L. A theory of ocular dominance. A.M.A. Archives of Ophthalmology, 1951, 45, 387-412.

(Received for publication June 29, 1978; revision accepted November 14, 1978.) 